\title{
Human bone marrow mesenchymal stromal/stem cells: current clinical applications and potential for hematology
}

\author{
Yasuo Miura ${ }^{1}$
}

Received: 30 November 2015 / Accepted: 30 November 2015 / Published online: 21 December 2015

(C) The Japanese Society of Hematology 2015

\begin{abstract}
Human mesenchymal stromal/stem cells (MSCs) have capabilities for multi-differentiation, immunomodulation, and hematopoietic support. Based on these unique biological characteristics, human MSCs have been extensively used as a transplantable resource for cell therapy in regenerative medicine, immune diseases, and hematological diseases. One of the most promising therapeutic effects of human MSCs is in hematopoietic stem cell transplantation for acute graft-versus-host disease (GVHD). Off-the-shelf MSC products are approved by regulatory agencies in some countries. In Japan, hematologists may soon have the option to use these products for the treatment of intractable acute GVHD. This review provides a brief overview of human MSCs including their fundamental characteristics, their clinical applications, and perspectives.
\end{abstract}

Keywords Human mesenchymal stromal/stem cells . Hematopoiesis $\cdot$ Clinical application

\section{Characteristics of human mesenchymal stromal/ stem cells (MSCs)}

\section{Isolation and culture of human MSCs}

Mesenchymal stem cells were originally isolated from bone marrow (BM) as adherent, fibroblast-like-shaped cells with the ability to differentiate into mesenchymal

Yasuo Miura

ym58f5@kuhp.kyoto-u.ac.jp

1 Department of Transfusion Medicine and Cell Therapy, Kyoto University Hospital, 54 Kawaharacho, Shogoin, Sakyo-ku, Kyoto 606-8507, Japan cell lineages such as osteoblasts, adipocytes, and chondrocytes [1, 2]. Stromal cells with similar biological characteristics to BM-derived mesenchymal stem cells have been isolated from a variety of organs and tissues including adipose tissue, umbilical cord blood [3], and dental pulp [4]. BM is easily accessible, and the isolation of mesenchymal stem cells from BM does not require complex procedures such as enzymatic digestion. Therefore, $\mathrm{BM}$ is one of the most appropriate sources of mesenchymal stem cells. To isolate mesenchymal stem cells, BM mononuclear cells are separated from BM aspirates by density gradient centrifugation. The isolated mononuclear cells were seeded onto a plastic dish and cultured in appropriate medium. Around 1 week later, colonies of adherent cells were observed (Fig. 1a). Primary cultures were passaged to disperse the colony-forming cells (passage 1). Expanded cells at passage 1-3 are usually utilized as mesenchymal stem cells for cell therapy. These cells are heterogeneous with regard to their stemness features. Mesenchymal stem cells are also known by other names such as mesenchymal progenitor cells, multi-potent mesenchymal stromal cells, mesenchymal cells, and stromal cells. In this review, these cells are called mesenchymal stromal/stem cells (MSCs).

An early study demonstrated that $1 \times 10^{6}$ MSCs per kg of recipient body weight are obtained from about $25 \mathrm{~mL}$ of BM aspirate after 37 days of culture (median; range 20-50 days) [5]. About $20 \times 10^{6}$ MSCs per kg of recipient body weight (median; range 8.0-35.8 $\times 10^{6}$ ) could be obtained at passage 4 [5]. In most clinical trials using MSCs, around $1 \times 10^{6}$ MSCs per $\mathrm{kg}$ of recipient body weight were infused once or multiple times. The expansion of MSCs from healthy adult BM is achieved in most cases. The appropriate number of cell passages, number of cells, and infusion schedule may depend on the target diseases. 
A

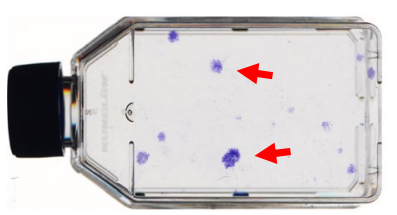

B

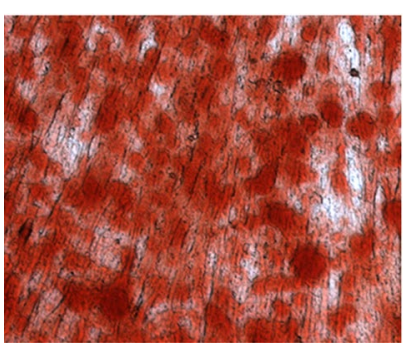

D

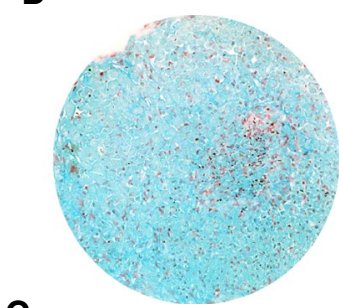

C

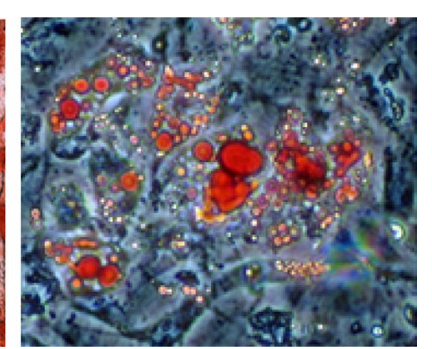

Fig. 1 Characteristics of human MSCs. a Colony formation (red arrows) as assessed by the CFU-F (colony-forming unit-fibroblast) assay. Toluidine blue $O$ staining is shown. b Osteogenic differentiation. Calcium deposition was assessed by Alizarin Red $S$ staining. c Adipogenic differentiation. Fat deposition was assessed by Oil Red $O$ staining. d Chondrogenic differentiation. Cartilage matrix deposition was assessed by Alcian blue staining

Therefore, it is important to clarify the optimal modality of MSC-based therapy in further investigations.

\section{Characteristics and definition of MSCs}

There are two principal methods to isolate MSCs: prospective isolation and conventional isolation. The prospective isolation method is based on cell sorting using surface markers that are expressed in MSCs [6]. This method has the advantage of isolating a homogenous cell population; however, it remains to be elucidated whether the cell number yield is sufficient to achieve efficacy in MSC-based cell therapies and whether such cells maintain their homogenous characteristics when expanded in vitro to a number sufficient for their therapeutic applications. The conventional isolation method is based on selecting cells that adhere to plastic dishes and form colonies, which are characteristics of MSCs. This method is simple and convenient; however, the isolated cells are heterogeneous.

MSCs used in clinical trials are isolated by the adhesion-based conventional selection method. In addition, MSCs are isolated from various tissues in a facilitydependent fashion. Therefore, it is critical to define the fundamental characteristics by which the isolated cells are designated as MSCs in order to compare MSC-based studies. For this purpose, the International Society of Cellular Therapy (ISCT) proposed the following minimal definition criteria for MSCs [7]: (1) the ability to adhere to plastic

plates; (2) the ability to differentiate into osteoblasts, adipocytes, and chondroblasts (Fig. 1b-d); and (3) the positive surface expression of CD105, CD73, and CD90 in the absence of surface human leukocyte antigen (HLA)-DR molecules and hematopoietic lineage markers of pan-leukocytes (CD45), endothelial/primitive cells (CD34), myeloid lineage cells (CD14 or CD11b), and B cell lineage cells (CD79 $\alpha$ or CD19) (Fig. 2). Because no other criteria are broadly accepted, it is conceivable to use these ISCT minimal definition criteria to define MSCs for clinical trials. However, MSCs have the ability to differentiate into neurogenic cells [4]. In addition, recent studies revealed that the therapeutic effects of MSCs are mainly mediated by soluble factors, such as cytokines, chemokines, and exosomes, rather than by their differentiation characteristics in lesions. The minimal definition criteria do not cover these features and are not sufficient for investigations. Therefore, for the development of MSC-based therapies, it is important that third parties verify the detailed properties of MSCs used in studies.

\section{Clinical applications of MSCs}

\section{Current status of clinical studies}

The first phase 1 clinical trial using MSCs was performed in 1995. In this study, autologous BM-derived MSCs were infused into patients with hematological malignancies as part of a safety and feasibility study [8]. A number of clinical trials using MSCs have been performed. As of April 2015, the clinical trial database "ClinicalTrials.gov" provided by the National Institutes of Health (USA) contained about 400 clinical trials using MSCs. In general, the infusion of MSCs appears to be well tolerated without severe infusion-associated adverse effects. A wide range of clinical applications of MSCs is registered for bone/cartilage disorders, cardiovascular diseases, diabetes mellitus, lung diseases, liver diseases, gastrointestinal diseases, hematological diseases, neuromuscular diseases, and cerebrovascular diseases. Clinical trials of human MSCs classified by disease types are listed in Fig. 3. Clinical trials of human MSCs for hematological disorders are listed in Table 1. Most clinical trials (78 \%) are in phase 1 (97 trials), phase 2 (70 trials), and phase 1/2 (142 trials). In total, 22 trials are in phase 3 and 13 trials are in phase 2/3. Encouraging results were reported from studies in phase 3 and phase $2 / 3$ for acute and/or chronic graft-versus-host disease (GVHD; four studies), Crohn's disease (four studies), acute myocardial infarction (three studies), cerebrospinal injury, and cerebrovascular diseases (Table 2). The most widely utilized source of MSCs is BM, followed by umbilical cord blood and adipose tissue. 
Fig. 2 Surface marker expression of human MSCs. Human MSCs are positive for CD105, CD73, and CD90, and negative for CD45, CD34, CD11b, CD19, and HLA-DR, as assessed by flow cytometric analysis

\begin{tabular}{|c|c|}
\hline Positive markers & Negative markers \\
\hline CD105, CD73, CD90 & CD45, CD34, CD14 or CD11b, CD79 $\alpha$ or CD19, HLA-DR \\
\hline
\end{tabular}

CD105

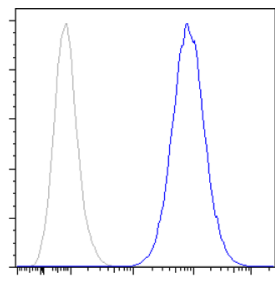

CD73

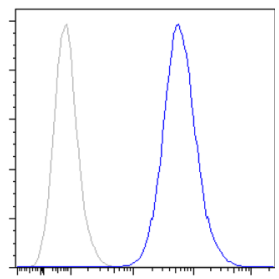

CD90

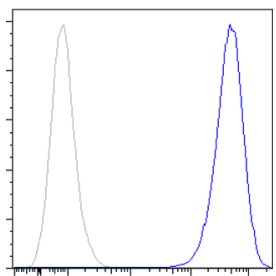

CD45

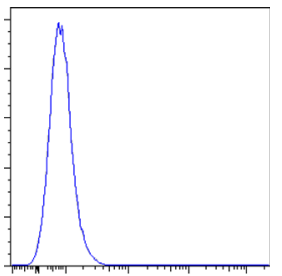

CD34

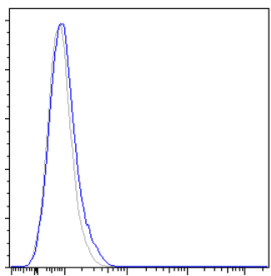

CD11b

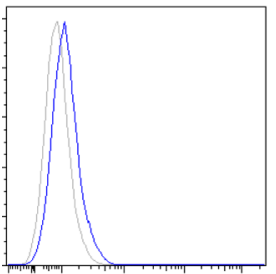

CD19

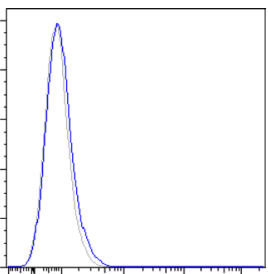

HLA-DR

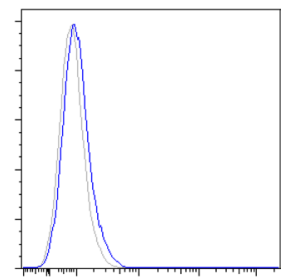

Table 1 Clinical trials of human MSCs for hematological diseases

GVHD

Acute/chronic

Treatment/prophylaxis

Graft failure/graft rejection

Treatment/prevention

Enhancement of hematopoietic recovery

Aplastic anemia

Expansion of cord blood cells

The data were obtained by searching the ClinicalTrials.gov website (http://www.clinicaltrials.gov) in April 2015. The keyword "mesenchymal stem cells" was used

allogeneic MSCs have been suggested to be beneficial for the treatment of diseases in which the immune system is dysregulated. The most significant clinical outcomes using MSCs observed to date are in the treatment of acute GVHD after hematopoietic stem cell transplantation (HSCT). In 2004, Le Blanc et al. [10] were the first to report a striking improvement in steroid-resistant severe grade IV acute GVHD of the gut and liver by intravenous infusion of BMderived MSCs from a haploidentical mother in a boy who had previously undergone unrelated HLA-matched HSCT for his acute lymphoblastic leukemia. A phase 2 study by the European Group for Blood and Marrow Transplantation 
Table 2 Disease conditions in phase $2 / 3$ and phase 3 clinical trials of human MSCs

Osteoarthritis
Cartilage injury
Bone defect
Osteochondritis
Osteonecrosis
Acute myocardial infarction
Ischemic cardiomyopathy
Chronic heart failure
Diabetes (Type 1, Type 2)
Diabetic neuropathy
GVHD (acute, chronic)
HSCT graft failure
Umbilical cord blood cell expansion
Crohn's disease
Liver cirrhosis
Ischemic-type biliary lesions
Spinal cord injury
Stroke
Cerebral palsy
Urinary incontinence

The data were obtained by searching the ClinicalTrials.gov website (http://www.clinicaltrials.gov) in April 2015. The keyword "mesenchymal stem cells" was used showed that infusion of MSCs from multiple donor sources conferred an overall response rate of $70 \%$ (39 of 55 cases) and a complete response rate of $55 \%$ (30 of 55 cases) for the treatment of steroid-resistant acute GVHD [11]. With regard to the therapeutic response, there was no difference in the number of cells infused, age, or HLA compatibility between the donor and recipient. It is of note that (1) a complete response was achieved by a single infusion of MSCs in 27 of 30 cases, after a median of 18 days (range 3-63 days); (2) the complete response rate was higher in children than in adults; (3) immunosuppressive therapy was ceased in eight cases; and (4) the overall survival rate at 2 years was better in cases with a complete response than in historical controls $(\sim 10 \%)$. This large study demonstrated that MSC infusion is an effective therapy for patients with steroid-resistant acute GVHD.

Since these studies were performed, off-the-shelf MSC products generated from adult human healthy volunteers were developed in clinical studies for the treatment of acute GVHD (Table 3) [12-15]. In a phase 2 trial to assess the efficacy of a MSC product $\left(\right.$ Prochymal $^{\circledR}$ ) in combination with steroids for a first-line therapy against acute GVHD, the effects of delivering $2 \times 10^{6}$ or $8 \times 10^{6} \mathrm{MSCs}$ per $\mathrm{kg}$ of recipient body weight in a single administration were compared. There was no difference in efficacy between these two doses [12]. Another study evaluated the efficacy

Table 3 Clinical studies of off-the-shelf MSC products in acute GVHD treatment

\begin{tabular}{|c|c|c|c|c|}
\hline & Wakatabe 2014 [15] & Kurtberg 2014 [14] & Prasid 2011 [13] & Kebriaei 2009 [12] \\
\hline MSC product & JR-031 & Prochymal $^{\circledR}$ & Prochymal $^{\circledR}$ & Prochymal $^{\circledR}$ \\
\hline \multirow[t]{2}{*}{ Status of acute GVHD } & \multirow[t]{2}{*}{$\begin{array}{l}\text { Grade 1ll-IV Steroid } \\
\text { refractory }\end{array}$} & $\begin{array}{l}\text { Grade B-D Steroid } \\
\text { refractory }\end{array}$ & $\begin{array}{l}\text { Grade 1ll-IV Steroid } \\
\text { refractory }\end{array}$ & Grade 11-IV \\
\hline & & $\begin{array}{l}\text { Refractory to one more } \\
\text { IST }\end{array}$ & $\begin{array}{l}\text { When other IST unavail- } \\
\text { able }\end{array}$ & First-line use with steroids \\
\hline $\begin{array}{l}\text { Patient age (years) } \\
\text { (median) }\end{array}$ & $5-66(33)$ & $0.2-17(7.8)$ & $0.4-15(4)$ & $34-67(52)$ \\
\hline Number of patients & 25 & 75 & 12 & 31 \\
\hline $\begin{array}{l}\text { MSC dose/recipient body } \\
\text { weight/administration }\end{array}$ & $2 \times 10^{6} / \mathrm{kg}$ & $2 \times 10^{6} / \mathrm{kg}$ & $\begin{array}{l}2 \times 10^{6} / \mathrm{kg}\left(8 \times 10^{6} / \mathrm{kg} \text { for }\right. \\
\text { initial } 2 \text { cases })\end{array}$ & $2 \times 10^{6} / \mathrm{kg}$ or $8 \times 10^{6} / \mathrm{kg}$ \\
\hline $\begin{array}{l}\text { Number of MSC adminis- } \\
\text { trations }\end{array}$ & $2 /$ week $\times 4$ weeks $=8$ & $1-20^{\mathrm{a}}$ & $2-21^{\mathrm{a}}$ & 2 \\
\hline \multirow[t]{3}{*}{ Outcome } & $\mathrm{CR}(n=6)$ & $\mathrm{OR}(=\mathrm{CR}+\mathrm{PR})$ & $\mathrm{CR}(n=7)$ & $\mathrm{CR}(n=24)$ \\
\hline & $\mathrm{PR}(n=9)$ & $\begin{array}{l}66.7 \% \text { (Grade B }) \\
76.2 \%(\text { Grade C) } \\
53.3 \%(\text { Grade D) }\end{array}$ & $\begin{array}{l}\mathrm{PR}(n=2) \\
\mathrm{MR}(n=3)\end{array}$ & $\mathrm{PR}(n=5)$ \\
\hline & $\begin{array}{l}\text { CR classified by organs } \\
\text { Gut, } 80 \% \\
\text { Skin, } 66.7 \% \\
\text { Liver, } 66.7 \% \\
60 \% \text { Survival at } 24 \text { weeks }\end{array}$ & $\begin{array}{l}\text { OR classified by organs } \\
\text { Gut, } 58.5 \% \\
\text { Skin, } 76.5 \% \\
\text { Liver, } 44.4 \%\end{array}$ & $\begin{array}{l}\text { Effective in gut GVHD } \\
\quad(\text { response rate }=75 \%)\end{array}$ & $\begin{array}{l}\text { No difference in efficacy } \\
\text { between MSC doses }\end{array}$ \\
\hline
\end{tabular}

The severity of acute GVHD was evaluated by Glucksberg grade (I-IV) or the International Bone Marrow Transplant Registry (IBMTR)

$C R$ complete response, $P R$ partial response, $M R$ mixed response, $O R$ overall response, $I S T$ immunosuppressive therapy

a Schedule: $2 /$ week $\times 4$ weeks $=8$ times (total) 
Table 4 Clinical studies of co-infusion of MSCs with HSCs in hematopoietic recovery

\begin{tabular}{|c|c|c|c|}
\hline & Le Blanc 2007 [21] & Ball 2007 [22] & Lazarus 2005 [20] \\
\hline Diseases & Hematological diseases & Hematological diseases & Hematological malignancies \\
\hline Patient age (years) (median) & $1-44(12)$ & $1-16(8)$ & $19-61(45)$ \\
\hline Number of patients & 7 & 14 & 46 \\
\hline HSCT & $\begin{array}{l}\text { PBSCT or BMT from HLA-identical } \\
\text { siblings or HLA-matched unre- } \\
\text { lated donors CBT }\end{array}$ & $\begin{array}{l}\text { PBSCT from HLA-haploidentical } \\
\text { related donors }\end{array}$ & $\begin{array}{l}\text { BMT or PBSCT from HLA-identical } \\
\text { siblings }\end{array}$ \\
\hline MSC donor & $\begin{array}{l}\text { HLA-identical siblings or HLA- } \\
\text { haploidentical related donors }\end{array}$ & HSC donor & HSC donor \\
\hline Outcome & $\begin{array}{l}\text { Eng, } 95 \% \text { Neut, } \geq 500 / \mu \mathrm{L} \text { at day } 12 \\
\text { PLT, } \geq 30,000 / \mu \mathrm{L} \text { at day } 10\end{array}$ & $\begin{array}{l}\text { Eng, } 100 \% \text { Neut, } \geq 500 / \mu \mathrm{L} \text { at day } \\
12 \text { PLT, } \geq 20,000 / \mu \mathrm{L} \text { at day } 10\end{array}$ & $\begin{array}{l}\text { Eng, } 100 \% \text { Neut, } \geq 500 / \mu \mathrm{L} \text { at day } \\
14 \mathrm{PLT}, \geq 20,000 / \mu \mathrm{L} \text { at day } 20\end{array}$ \\
\hline MSC co-infusion & IV $0-4 \mathrm{~h}$ after HSCT & IV $4 \mathrm{~h}$ before HSCT & IV $4 \mathrm{~h}$ before HSCT \\
\hline
\end{tabular}

$H S C T$ hematopoietic stem cell transplantation, $P B S C T$ peripheral blood stem cell transplantation, $B M T$ bone marrow transplantation, $I V$ intravenous administration, Neut neutrophil, PLT platelet, Eng engraftment

of Prochymal ${ }^{\circledR}$ for the treatment of steroid-resistant acute GVHD in children as a third-line therapy [14]. The study reported overall response rate of $61.3 \%$, and survival rate of $76.1 \%$ for complete and partial responders, versus $27.6 \%$ for non-responders at day 100 [14]. The results of clinical studies using mesenchymal stem cell products in Japan have been reported $[15,16]$. In a phase $2 / 3$ trial, 6 of 25 patients had a complete response $(24 \%)$ and 9 of 25 patients had a partial response (36\%) [15]. In addition, the survival rate was $60 \%$ at 24 weeks and $93.3 \%$ among patients with a good response. Notably, a complete response was achieved in $80 \%$ of patients with GVHD of the gut. MSCs products have been approved for the treatment of GVHD in Canada, New Zealand, and Japan.

However, the preliminary results of a phase 3 study reported no significant advantage of a sustained complete response in adults. Because MSCs have immunosuppressive effects, attention may need to be paid to the incidence of infections, such as invasive fungal infections and viral infections, upon MSC-based therapy [17]. Many studies of individual donor-derived MSCs reported efficacy with a single administration of MSCs (from one donor to one recipient). Off-the-shelf MSC products are produced from one donor for multiple administrations and/or multiple donors. Repeated expansion of MSCs may deteriorate their quality or heterogeneity, thereby reducing their therapeutic effects [18].

\section{Engraftment and recovery of hematopoiesis}

One of the important roles of MSCs in BM is to provide a microenvironment for hematopoietic stem and progenitor cells and to support durable and effective hematopoiesis. Toxic conditioning in HSCT impairs the function of recipient MSCs to maintain niches for such cells [19]. In an early study, co-infusion of autologous peripheral blood (PB) progenitor cells and MSCs in breast cancer patients receiving high-dose chemotherapy efficiently enhanced hematopoietic recovery [5]. However, in myeloablative allogeneic HSCT using BM or PB progenitor cells from HLA-identical siblings, co-transplantation of MSCs showed no apparent acceleration of engraftment (Table 4) [20]. Upon graft failure or graft rejection after the first allogeneic HSCT, a pilot study showed the utility of co-infusion of MSCs in the subsequent salvage HSCT to improve engraftment of the second graft (Table 4) [21]. In haploidentical allogeneic HSCT using cytokine-mobilized CD34-positive progenitor cells, co-transplantation of haploidentical MSCs did not accelerate neutrophil or platelet engraftment, but prevented graft rejection (Table 4) [22]. In unrelated HLA-mismatched umbilical cord blood transplantation for children with high-risk hematological malignancies, co-transplantation of haploidentical parental MSCs supported relatively rapid hematopoietic recovery [23]. Although MSC infusion did not confer enhanced hematopoietic engraftment in a standard HSCT condition from HLA-identical siblings with myeloablative conditionings [20], it is of note that MSC infusion was effective in some cases at high risk of graft failure, graft rejection, and delayed hematopoietic recovery [21-23]. After allogeneic HSCT, the chimerism of MSCs is mostly recipient type, which implies that the hematopoiesis-supportive effect of MSCs is not dependent on the sustained engraftment of donor MSCs in recipient BM [24]. The hematopoiesis-supportive function of MSCs is considered to be mediated by soluble factors that stimulate infused donor hematopoietic cells and/or repair recipient MSCs damaged by toxic conditioning, although this has not been elucidated.

Recently, de Lima et al. [25] reported that hematopoietic recovery was accelerated by transplantation of two types of umbilical cord blood (double cord blood transplantation): One umbilical cord blood unit was not manipulated and 
the other was expanded in ex vivo co-cultures with MSCs. Their strategy was unique in that (1) early hematopoietic recovery was achieved by the manipulated umbilical cord blood unit with a smaller cell number because the number of hematopoietic progenitor cells was increased in co-cultures with MSCs and (2) long-term hematopoietic reconstitution was guaranteed by the non-manipulated umbilical cord blood unit with a higher cell number.

These pilot studies suggest the utility of MSCs for hematopoietic recovery after allogeneic HSCT. Further studies are needed to elucidate the appropriate dose of MSCs and the timing of their infusion for achieving optimal outcomes.

\section{Perspectives of MSC-targeted therapy}

In general, MSCs are expanded ex vivo to obtain a sufficient "quantity" of cells necessary to achieve their therapeutic effects. However, this may lower the quality of MSCs and reduce their therapeutic function after repeated cell passage. Consistent with their biological features, MSCs express various molecules such as integrins, cytokines and growth factor receptors, and adhesion molecules [26]. We propose that the future direction of MSCbased therapy should include pharmacological upregulation of their "quality" of function. In preclinical studies, we demonstrated that simulation of MSCs with erythropoietin and parathyroid hormone enhances MSC-mediated bone formation, hematopoiesis, and tissue regeneration [27-29].

The roles of various stromal cells that have similar characteristics to MSCs in physiological hematopoiesis have been extensively investigated using genetic animal models. In addition, pathological hematopoiesis is caused by a primary genetic abnormality in MSC-derived osteoprogenitor cells [30]. Endogenous MSCs in the host BM microenvironment critically contribute not only to physiological hematopoiesis but also to pathological hematopoiesis, including leukemia. My laboratory demonstrated that $\mathrm{C} / \mathrm{EBP} \beta$ expressed by MSCs plays a crucial role in physiological precursor B cell lymphopoiesis in mice [31]. My laboratory also showed that proteasome inhibitors abolish the interactions of human B cell precursor acute lymphoblastic leukemia cells with human MSCs and restore the chemosensitivity of these leukemia cells [32]. To date, pharmacological therapy in hematology mostly targets hematopoietic cells. We propose that pharmacological targeting of MSCs is a novel strategy to overcome the shortcomings of conventional pharmacotherapies in the treatment of hematological diseases.

With regard to the development of pharmacological MSC-targeting therapy, approved drugs, such as erythropoietin, parathyroid hormone, and proteasome inhibitors, should be used because safety and toxicity examinations can be omitted or simplified, resulting in their early clinical use (so-called drug repositioning).

\section{Summary}

This review focuses on human MSCs and describes their fundamental biological characteristics, current status, and future potential in clinical applications. Human MSCs are heterogeneous and probably comprise stromal cells with different and distinctive therapeutic characteristics. Therefore, further studies are needed to clarify the nature of human MSCs in order to establish the optimal MSCbased therapy that has the potential to treat various diseases throughout the entire body.

Acknowledgments The author thanks Dr. Masaki Iwasa, Dr. Aya Fujishiro, Dr. Sumie Fujii, Dr. Noriko Sugino, Dr. Satoshi Yoshioka, and Dr. Hisayuki Yao for their critical reading of this manuscript. The author is also grateful to Prof. Taira Meakwa, Prof. Akifumi-Takaori Kondo, and Prof. Tatsuo Ichinohe for their advice on MSC studies.

Grants This work was supported in part by a Grant-in-Aid from the Ministry of Education, Culture, Sports, Science and Technology in Japan (Y.M.). This work was also supported in part by the Joint Usage/Research Center of Hiroshima University Research Institute for Radiation Biology and Medicine (Y.M.) and the Takeda Science Foundation (Y.M.).

\section{Compliance with ethical standards}

Conflict of interest The author declares that he has no conflict of interest.

\section{References}

1. Friedenstein AJ, Petrakova KV, Kurolesova AI, Frolova GP. Heterotopic of bone marrow. Analysis of precursor cells for osteogenic and hematopoietic tissues. Transplantation. 1968;6:230-47.

2. Pittenger MF, Mackay AM, Beck SC, Jaiswal RK, Douglas R, Mosca JD, et al. Multilineage potential of adult human mesenchymal stem cells. Science. 1999;284:143-7.

3. Yoshioka S, Miura Y, Iwasa M, Fujishiro A, Yao H, Miura M, et al. Isolation of mesenchymal stromal/stem cells from smallvolume umbilical cord blood units that do not qualify for the banking system. Int J Hematol. 2015;102:218-29.

4. Miura M, Gronthos S, Zhao M, Lu B, Fisher LW, Robey PG, et al. SHED: stem cells from human exfoliated deciduous teeth. Proc Natl Acad Sci USA. 2003;100:5807-12.

5. Koç ON, Gerson SL, Cooper BW, Dyhouse SM, Haynesworth SE, Caplan AI, et al. Rapid hematopoietic recovery after coinfusion of autologous-blood stem cells and culture-expanded marrow mesenchymal stem cells in advanced breast cancer patients receiving high-dose chemotherapy. J Clin Oncol. 2000;18:307-16.

6. Morikawa S, Mabuchi Y, Niibe K, Suzuki S, Nagoshi N, Sunabori $\mathrm{T}$, et al. Development of mesenchymal stem cells partially originate from the neural crest. Biochem Biophys Res Commun. 2009;379:1114-9. 
7. Dominici M, Le Blanc K, Mueller I, Slaper-Cortenbach I, Marini F, Krause D, et al. Minimal criteria for defining multipotent mesenchymal stromal cells. The International Society for Cellular Therapy position statement. Cytotherapy. 2006;8:315-7.

8. Lazarus HM, Haynesworth SE, Gerson SL, Rosenthal NS, Caplan AI. Ex vivo expansion and subsequent infusion of human bone marrow-derived stromal progenitor cells (mesenchymal progenitor cells): implications for therapeutic use. Bone Marrow Transplant. 1995;16:557-64.

9. Ozaki K, Sato K, Oh I, Meguro A, Tatara R, Muroi K, et al. Mechanisms of immunomodulation by mesenchymal stem cells. Int J Hematol. 2007;86:5-7.

10. Le Blanc K, Rasmusson I, Sundberg B, Götherström C, Hassan M, Uzunel M, et al. Treatment of severe acute graft-versus-host disease with third party haploidentical mesenchymal stem cells. Lancet. 2004;363:1439-41.

11. Le Blanc K, Frassoni F, Ball L, Locatelli F, Roelofs H, Lewis I, et al. Mesenchymal stem cells for treatment of steroid-resistant, severe, acute graft-versus-host disease: a phase II study. Lancet. 2008;371:1579-86.

12. Kebriaei P, Isola L, Bahceci E, Holland K, Rowley S, McGuirk J, et al. Adult human mesenchymal stem cells added to corticosteroid therapy for the treatment of acute graft-versus-host disease. Biol Blood Marrow Transplant. 2009;15:804-11.

13. Prasad VK, Lucas KG, Kleiner GI, Talano JA, Jacobsohn D, Broadwater G, et al. Efficacy and safety of ex vivo cultured adult human mesenchymal stem cells (Prochymal ${ }^{\mathrm{TM}}$ ) in pediatric patients with severe refractory acute graft-versus-host disease in a compassionate use study. Biol Blood Marrow Transplant. 2011;17:534-41.

14. Kurtzberg J, Prockop S, Teira P, Bittencourt H, Lewis V, Chan $\mathrm{KW}$, et al. Allogeneic human mesenchymal stem cell therapy (remestemcel-L, Prochymal) as a rescue agent for severe refractory acute graft-versus-host disease in pediatric patients. Biol Blood Marrow Transplant. 2014;20:229-35.

15. Watakabe K, Miyamura K, Ozawa Y, Okada M, Yamashita T, Murata M, et al. Efficacy of mesenchymal stem cells for the treatment of steroid-refractory aGVHD. Blood. 2014;124:3913.

16. Muroi K, Miyamura K, Ohashi K, Murata M, Eto T, Kobayashi $\mathrm{N}$, et al. Unrelated allogeneic bone marrow-derived mesenchymal stem cells for steroid-refractory acute graft-versus-host disease: a phase I/II study. Int J Hematol. 2013;98:206-13.

17. Remberger M, Olle Ringdén $O$. Treatment of severe acute graft-versus-host disease with mesenchymal stromal cells: a comparison with non-MSC treated patients. Int J Hematol. 2012;96:822-4.

18. von Bahr L, Sundberg B, Lönnies L, Sander B, Karbach H, Hägglund $\mathrm{H}$, et al. Long-term complications, immunologic effects, and role of passage for outcome in mesenchymal stromal cell therapy. Biol Blood Marrow Transplant. 2012;18:557-64.

19. Iwasa M, Miura Y, Fujishiro A, Tamura A, Sato A, Yokota A, et al. Effects of irradiation on the functional characteristics of human bone marrow mesenchymal stromal/stem cells. Blood. 2014;124:1589.
20. Lazarus HM, Koc ON, Devine SM, Curtin P, Maziarz RT, Holland HK, et al. Cotransplantation of HLA-identical sibling culture-expanded mesenchymal stem cells and hematopoietic stem cells in hematologic malignancy patients. Biol Blood Marrow Transplant. 2005;11:389-98.

21. Le Blanc K, Samuelsson H, Gustafsson B, Remberger M, Sundberg B, Arvidson J, et al. Transplantation of mesenchymal stem cells to enhance engraftment of hematopoietic stem cells. Leukemia. 2007;21:1733-8.

22. Ball LM, Bernardo ME, Roelofs H, Lankester A, Cometa A, Egeler RM, et al. Cotransplantation of ex vivo expanded mesenchymal stem cells accelerates lymphocyte recovery and may reduce the risk of graft failure in haploidentical hematopoietic stem-cell transplantation. Blood. 2007;110:2764-7.

23. Macmillan ML, Blazar BR, DeFor TE, Wagner JE. Transplantation of ex vivo culture-expanded parental haploidentical mesenchymal stem cells to promote engraftment in pediatric recipients of unrelated donor umbilical cord blood: results of a phase I-II clinical trial. Bone Marrow Transplant. 2009;43:447-54.

24. Miura Y, Yoshioka S, Yao H, Takaori-Kondo A, Maekawa T, Ichinohe T. Chimerism of bone marrow mesenchymal stem/stromal cells in allogeneic hematopoietic cell transplantation: is it clinically relevant? Chimerism. 2013;4:78-83.

25. de Lima M, McNiece I, Robinson SN, Munsell M, Eapen M, Horowitz M, et al. Cord-blood engraftment with ex vivo mesenchymal-cell coculture. N Engl J Med. 2012;367:2305-15.

26. Deans RJ, Moseley AB. Mesenchymal stem cells: biology and potential clinical uses. Exp Hematol. 2000;28:875-84.

27. Yamaza T, Miura Y, Bi Y, Liu Y, Akiyama K, Sonoyama W, et al. Pharmacologic stem cell based intervention as a new approach to osteoporosis treatment in rodents. PLoS ONE. 2008;3:e2615.

28. Yamaza T, Miura Y, Akiyama K, Bi Y, Sonoyama W, Gronthos $\mathrm{S}$, et al. Mesenchymal stem cell-mediated ectopic hematopoiesis alleviates aging-related phenotype in immunocompromised mice. Blood. 2009;113:2595-604.

29. Yao H, Miura Y, Yoshioka S, Miura M, Hayashi Y, Tamura A, et al. Parathyroid hormone enhances hematopoietic expansion via upregulation of cadherin-11 in bone marrow mesenchymal stromal cells. Stem Cells. 2014;32:2245-55.

30. Raaijmakers MH, Mukherjee S, Guo S, Zhang S, Kobayashi T, Schoonmaker JA, et al. Bone progenitor dysfunction induces myelodysplasia and secondary leukaemia. Nature. 2010;464:852-7.

31. Yoshioka S, Miura Y, Yao H, Satake S, Hayashi Y, Tamura A, et al. CCAAT/enhancer-binding protein $\beta$ expressed by bone marrow mesenchymal stromal cells regulates early B-cell lymphopoiesis. Stem Cells. 2014;32:730-40.

32. Iwasa M, Miura Y, Fujishiro A, Fujii S, Sugino N, Yoshioka S, et al. Bortezomib attenuates adhesion of B cell precursor acute lymphoblastic leukemia cells to bone marrow mesenchymal stro$\mathrm{mal} / \mathrm{stem}$ cells via down-regulating SPARC expression. Blood. $2015 ; 124: 224$. 